\title{
A LOCALIZED OUTBREAK OF DENGUE FEVER IN KUALA LUMPUR: SEROLOGICAL ASPECTS*
}

\author{
By C. E. GORDON SMITH \\ Virus Research Officer, Institute for Medical Research, \\ Kuala Lumpur
}

(With 11 Figures in the Text)

\begin{abstract}
A localized outbreak of dengue involving about forty cases occurred in and around a Kuala Lumpur girls' school in March 1954. The clinical and epidemiological aspects of this outbreak (Smith, 1956a) and the isolation of type 1 dengue virus from three of the cases (Smith, 1956b) have been described. This paper describes a serological study of the cases in this outbreak. As there has been no previous account published of the use of all the serological techniques for dengue diagnosis in a naturally occurring outbreak, the results are discussed in detail.
\end{abstract}

\section{METHODS AND MATERIALS}

(1) Sera. Sera were taken from clotted blood samples after overnight storage at $4^{\circ} \mathrm{C}$; ; they were then centrifuged and stored frozen at $-20^{\circ} \mathrm{C}$., being thawed for testing as infrequently as possible. Whenever possible, acute-phase samples were obtained from cases during the first few days of illness, followed by convalescentphase samples 2-3 weeks later. In addition to these, some samples were obtained before onset of fever, and other serial samples from girls who did not become ill.

(2) Viruses. (a) Dengue-1, CHIA strain: isolated from a patient in this outbreak (Smith, 1956b).

(b) Dengue-1, Hawaii strain; 115th mouse passage obtained from Walter Reed Army Institute of Research, Washington (WRAIR).

(c) Dengue-2, New Guinea ' $C$ ' strain; 20th mouse passage obtained from WRAIR.

(d) Japanese encephalitis (JE), Nakayama strain; 46th mouse passage obtained from WRAIR.

(3) Neutralization tests. Dengue seed viruses were prepared from the brains of moribund suckling mice which had been inoculated intracerebrally (i/c); JE seed virus was prepared in the same way from 4-6 g. mice. All the mice used in this study were of the DDM strain. Seed virus was stored in dry ice in ampoules as a $20 \%$ suspension of mouse-brain in normal rabbit serum. In brief, the neutralization tests consisted of incubating tenfold dilutions of virus with equal volumes $(0.25 \mathrm{ml}$.) of the sera to be tested, then inoculating each serum-virus mixture $\mathrm{i} / \mathrm{c}$ into six mice. Inactivated normal rabbit serum (heated at $56^{\circ} \mathrm{C}$. for $30 \mathrm{~min}$.) was used as a non-immune control. The period of incubation of serum-virus mixtures

\footnotetext{
*This paper formed part of a Thesis presented to the University of St Andrews for the degree of M.D.
} 
at $37^{\circ} \mathrm{C}$. was exactly $30 \mathrm{~min}$. for JE (Paterson, Ley, Wisseman, Pond, Smadel, Diercks, Hetherington, Sneath, Witherington \& Lancaster, 1952), and exactly $2 \mathrm{hr}$. for dengue (Sabin, 1950). JE virus was diluted in 10\% inactivated rabbit serum in saline (RSS), while the dengue viruses were diluted in fresh normal guinea-pig serum (GPS) in order to supply the heat-labile factor of normal serum (Sabin, 1950). The sera under test were not inactivated. The titres of the virus in the presence of each serum under test, and of the control serum, were estimated by plotting the probits of the percentage mortality in each group of mice against the corresponding log virus dose and fitting a straight line. The point where the line cut the probit 5 was taken as the $\mathrm{LD}_{50}$. The $\log$ neutralizing index (log NI) of a serum sample is the difference between the $\log \mathrm{LD}_{50}$ of the virus after incubation with the serum, and the $\log \mathrm{LD}_{50}$ of the same virus after identical incubation with control serum, or, in other words, the neutralizing index (NI) is the number-fold neutralization by the serum under test, compared with the control $(\mathrm{NI}=1)$.

(4) Haemagglutinin-inhibition test. The test as described by Chanock \& Sabin (1954) was used, employing 16 units of antigen and a final $\mathrm{pH}$ of $6 \cdot 5$. Sera were twice extracted with acetone to remove normal inhibitor before testing. Partial inhibition of haemagglutination was taken as the end-point and the results are quoted as the reciprocal of the highest serum dilution (before addition of antigen and cells) which partially inhibited haemagglutination by 16 units of antigen. Tests were carried out in M.R.C.-pattern Perspex plates.

(5) Complement-fixation test. Antigens were prepared by the acetone-ether extraction method of Casals \& Olitsky (1951) and were stored in dry ice. An antigen prepared in the same way from normal mouse brain was used as a control. The test was set up in $0 \cdot 1 \mathrm{ml}$. volumes using 4 units of antigen, and 2 exact units of complement (preserved by Richardson's method-Mackie \& McCartney, 1950). After overnight incubation at $4^{\circ} \mathrm{C} ., 0.2 \mathrm{ml}$. containing equal volumes of 5 MHD of amboceptor, and $0.5 \%$ sheep cells which had been incubated for $1 \mathrm{hr}$. at $37^{\circ} \mathrm{C}$. was added to each tube. Sera were inactivated at $60^{\circ} \mathrm{C}$. for $30 \mathrm{~min}$. before testing. The technique is essentially the same as that employed by Stoker (1953) for Q fever for which the method was originally adopted in this laboratory. Barbituratebuffered calcium-magnesium saline (Fulton \& Dumbell, 1949) was used as a diluent. Four- or three-plus fixation read after incubation at $37^{\circ} \mathrm{C}$. for $30 \mathrm{~min}$. after addition of sensitized cells was taken as positive (i.e. nil to $25 \%$ haemolysis). Results are recorded as the reciprocal of the highest initial serum dilution which caused 3- or 4-plus fixation.

\section{RESULTS}

\section{Diagnosis}

(1) Neutralization tests. The term 'neutralizing index' has been loosely applied to both $(a)$ the difference between the $\log \mathrm{LD}_{50}$ titre of virus obtained after incubation with the test serum and that obtained with a negative control serum, and (b) the difference in $\log \mathrm{LD}_{50}$ titre of virus obtained after incubation with acutephase and with convalescent-phase sera from same patient. In this paper, as was stated above, the term 'log neutralizing index' is confined to log differences 
from a control negative serum, while the log difference between acute- and convalescent-phase sera is described as the log rise-in-titre-or its antilog as the number-fold rise-in-titre, which brings the terminology into line with that of other serological tests.

The extent of rise-in-titre acceptable as diagnostic of infection with a given virus is very difficult to define because it depends on the day of disease of the first specimen of serum obtained and also on the interval between the two specimens. There is, in addition, a considerable variation between different individuals in the time after infection at which the antibody level starts to rise. Table 1 lists all the results of patients in this outbreak from whom paired acute- and convalescentphase sera were obtained and it can be seen that the geometric mean rise-in-titre of neutralizing antibody obtained during the first 3 weeks of the disease was about 60-fold versus dengue-1 virus, 15-fold versus dengue-2 virus, but only 5-fold versus JE virus. The range of rises-in-titre is of course more important. More than half had at least a 100-fold increase in neutralizing antibody versus dengue- $I$, but five had less than a five-fold increase during the first 3 weeks or so. The following additional information is, however, available about these five cases:

(i) I.H. had a neutralizing index of 80 versus $\mathrm{JE}$ and of 160 versus dengue-l on the 6th day. This may indicate that there had been previous infection with dengue, JE or with a related virus. There was another case (R.J.) with a late rise-in-titre from whom a first specimen of serum was obtained on the 18th day after onset of the disease and a second specimen on the 66th day. She showed a 100 -fold risein-titre of neutralizing antibody versus dengue- 1 and dengue- 2 between these days, but only a ten-fold rise versus JE. I.H. might, on the other hand, have had an accelerated response even by the 6 th day.

(ii) F.S. had a poor antibody response, but probably showed significant rises-intitre later (cf. H.M.Y. below).

(iii) H.M.Y. had a late rise in neutralizing antibody titre. Comparing sera at the Ist and the 67th days of disease, she showed a 1200-fold rise against dengue-1, and a 100-fold rise against dengue-2, and no rise against JE.

(iv) S.S.C. had previous antibody against dengue-1 (NI 63) and dengue-2 (NI 63) and was febrile only for 1 day. She had a modified illness apparently due to previous infection with dengue, or with a closely related virus.

(v) C.V.F. probably had previous antibody to dengue-1 (NI 32), but may, on the other hand, have had merely a delayed response.

Only in the case of C.K.L. was there apparently a greater rise against dengue-2 than dengue-1, but the difference is not significant $(0 \cdot 1 \mathrm{log})$. Versus dengue-2 only four patients showed a rise-in-titre of 100 -fold or more, while eight had rises less than 50-fold. Against JE virus only one patient showed more than a 100-fold rise and she had previous neutralizing antibody to this virus. The United States Army Neurotropic Virus Disease Commission (quoted by Smadel, 1952) regards rises of 50 -fold or greater as diagnostic. This would only permit 8/12 of the cases in Table 1 to be diagnosed as dengue infections. Figs. 1-3, however, show that testing of later specimens of serum would detect a sufficient rise-in-titre and that, as antibody to heterotypic virus (dengue-2) falls off more quickly than that to homotopic 
virus (dengue-1), later specimens would also distinguish infections due to related viruses more clearly.

The results of the neutralization tests are depicted in Figs. 1-3 along with the geometric means of groups of observations between 0 and 6 days, 14 and 28 days,

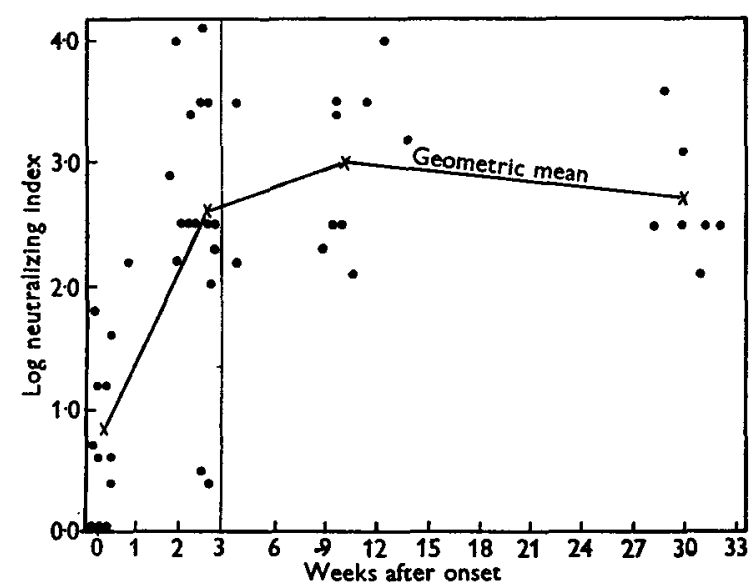

Fig. 1. Neutralizing antibody titres versus type 1 dengue virus during and after an attack of type 1 dengue fever.

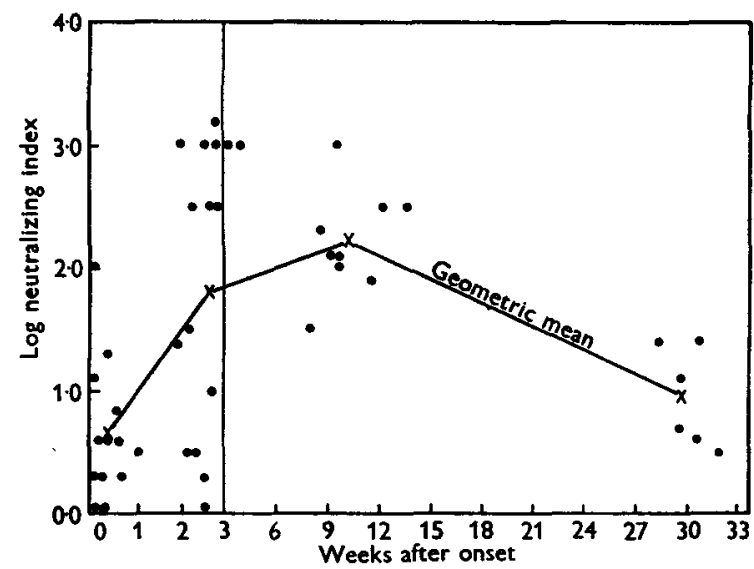

Fig. 2. Neutralizing antibody titres versus type 2 dengue virus during and after an attack of type 1 dengue fever.

55 and 86 days, and 196 and 224 days after onset. The degree of scatter is clearly wide. The object of these figures is to show the trends; individual cases do not of course necessarily follow the course of the geometric mean.

(2) Haemagglutinin-inhibition tests. Reference to Table 1 shows that all the cases reported here had at least a fourfold rise-in-titre against CHIA and Hawaii dengue-1 antigens. All except one had a fourfold or greater rise-in-titre versus dengue- 2 antigen, and it can be seen that the ranges and geometric means are not significantly different for the three dengue antigens. Both the geometric mean and the range of rises-in-titre versus $\mathrm{JE}$ antigen are less, but such a finding would be 
available only where serial sera from a number of cases in an outbreak had been tested against all antigens. In the individual case, it is often difficult to distinguish infections with JE from those with dengue by this test, as for example in cases I.H., C.K.L. and H.M.Y. The geometric means of grouped observations at different stages of the disease are plotted in figs. 4-7 to demonstrate the trend of the anti-

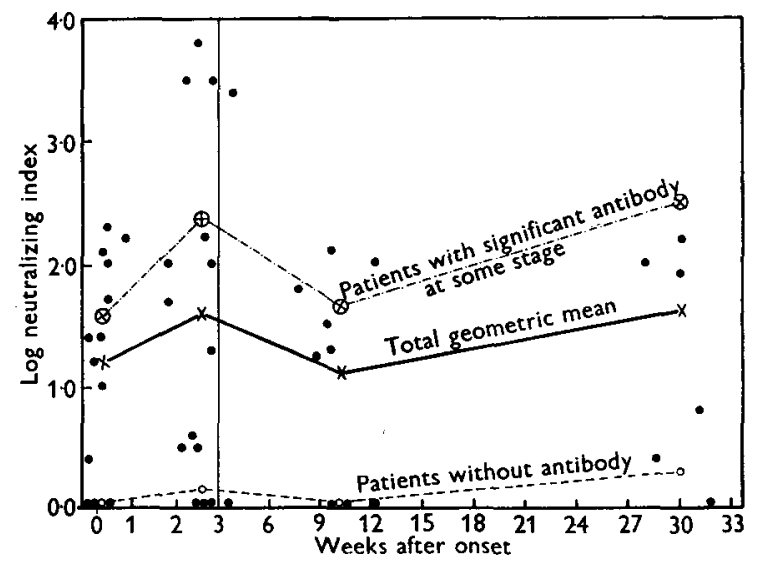

Fig. 3. Neutralizing antibody titres versus Japanese encephalitis virus during and after an attack of type 1 dengue fever.

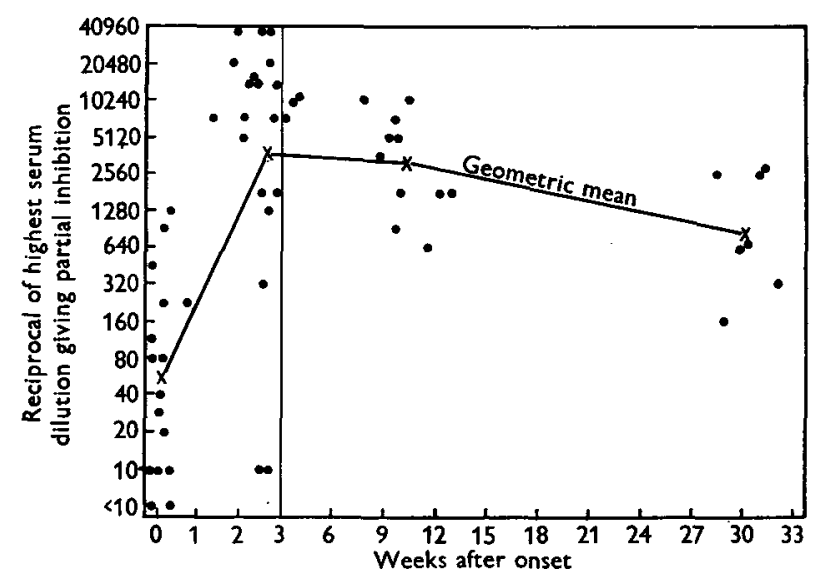

Fig. 4. Haemagglutinin-inhibiting antibody titres versus CHIA virus during and after an attack of dengue due to that virus.

body curve and the points plotted show the range of observations on which this is based. It is evident that in individual cases wide variations from the mean can be expected. The same variation in the time of rise-in-titre is seen as with the neutralization test: the scatter is wide in the first weeks, narrowing thereafter. There is no difference between the results versus CHIA and dengue-1, as would be expected. There is a sharp rise in titre during the first few weeks followed by a slow fall amounting to less than fourfold in the geometric mean by the end of 6 months. The general shape of the mean curve for dengue-2 runs about twofold lower, and for JE about fourfold lower, than that of dengue-1 throughout. 


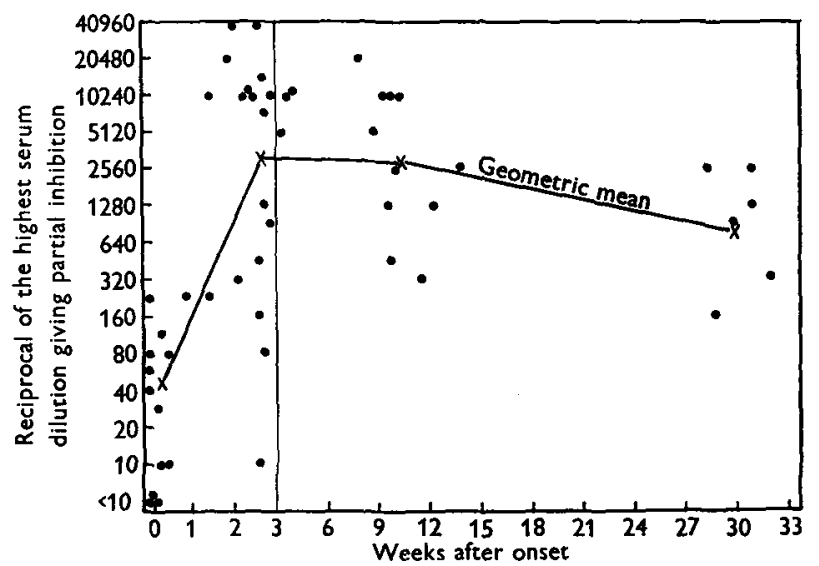

Fig. 5. Haemagglutinin-inhibiting antibody titres versus type 1 dengue virus during and after an attack of type 1 dengue fever.

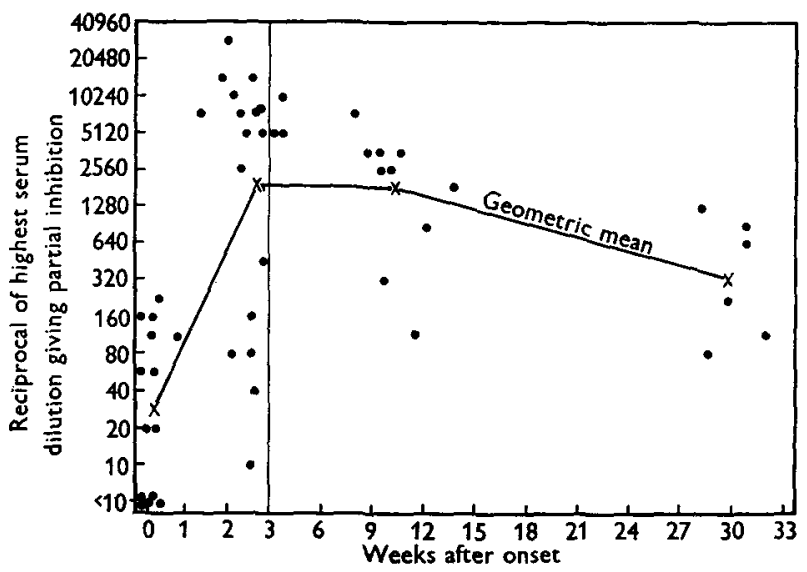

Fig. 6. Haemagglutinin-inhibiting antibody titres versus type 2 dengue virus during and after an attack of type 1 dengue fever.

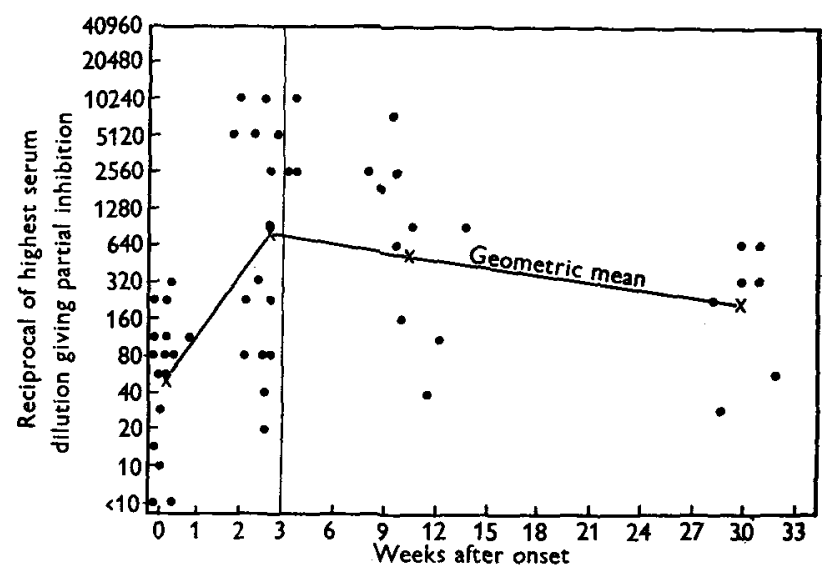

Fig. 7. Haemagglutinin-inhibiting antibody titres versus Japanese encephalitis virus during and after an attack of type 1 dengue fever. 
Obviously the HI-test is of little value in distinguishing infections due to the three viruses. Its main value lies in an outbreak where some cases have been clearly identified as type 1 or 2 dengue, or as Japanese encephalitis; the test can then be used for the diagnosis of subsequent cases by demonstration of a rise-intitre of HI antibody. Sweet \& Sabin (1954), from a study of four experimentallyinfected volunteers, suggested that the HI test was the diagnostic test of choice. This is not so in areas where more than one related virus is endemic. Clinical differentiation of florid cases of dengue and encephalitis is of course easy, but as infections with these and many other viruses may cause only fever (pyrexias of unknown origin), cross-reactions are important.

(3) Complement-fixation tests. In the complement-fixation test a fourfold rise in antibody titre during the course of the illness is generally accepted as diagnostic of infection with the infectious agent concerned. Table 1 shows that with dengue-1 antigen at least a fourfold rise-in-titre was obtained in all except two cases (H.M.Y. and W.K.P.). By the 67th day, H.M.Y. had shown a 256-fold rise and it is not unlikely that W.K.P. also had a later increase in antibody. Similar results were obtained with dengue- 2 and $\mathrm{JE}$ antigens, and there was no significant difference in mean or range between tests with the two dengue viruses and with JE by the complement-fixation test.

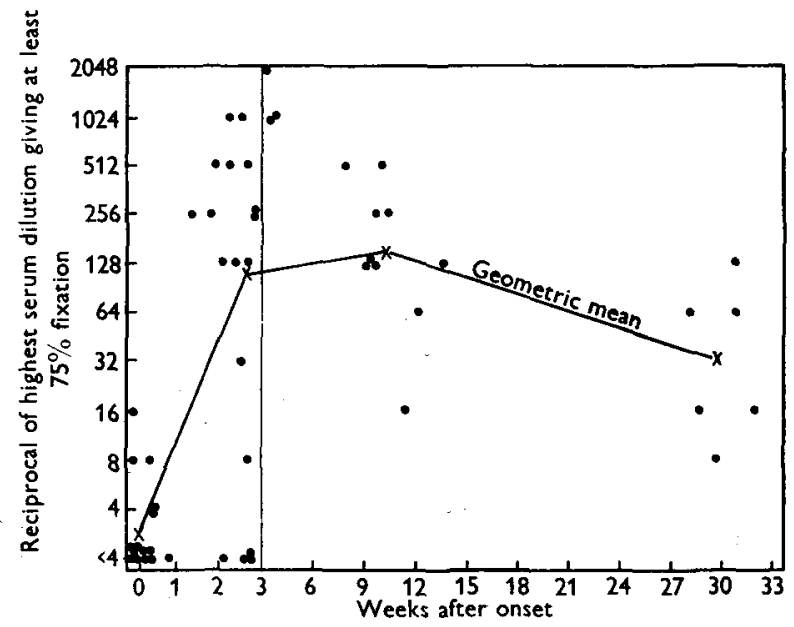

Fig. 8. Complement-fixing antibody titres versus type 1 dengue virus during and after an attack of type 1 dengue fever.

The individual titres obtained and their geometric means are shown in Figs. 8-10. The scatter of results is fairly wide during the first 3 weeks, indicating differences in the time of rise-in-titre. The mean rises-in-titre were, however, all about 64-fold. The titre against all three viruses rose sharply in the first 3 weeks, was maintained for about 2 months and had fallen fourfold to eightfold by the 6th month. There was nothing to distinguish results versus one virus from those against another, Using the technique described above, the complement-fixation test is clearly of no value in distinguishing infections by these viruses and, as it is more difficult in 


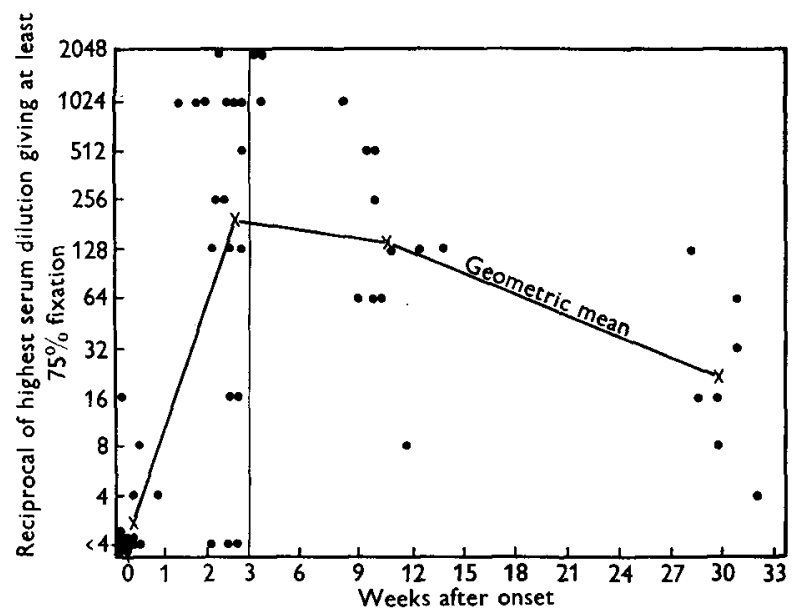

Fig. 9. Complement-fixing antibody titres versus type 2 dengue virus during and after an attack of type 1 dengue fever.

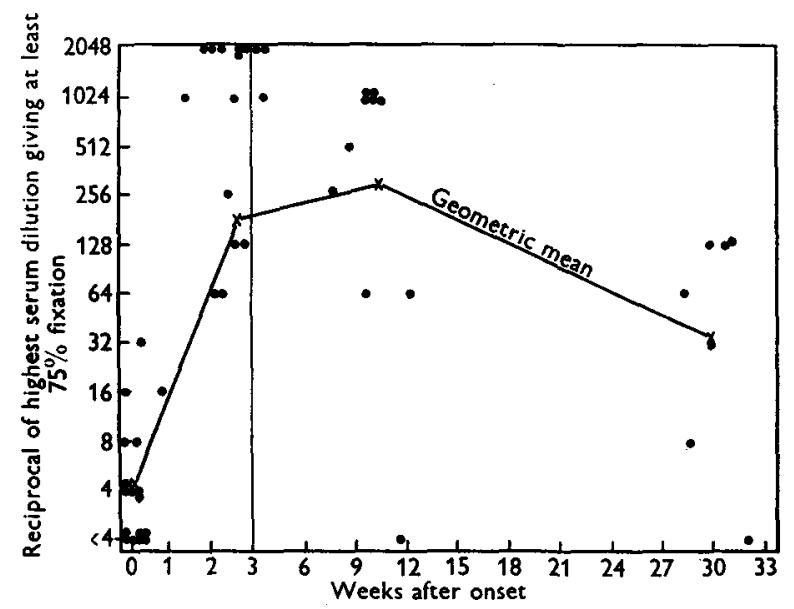

Fig. 10. Complement-fixing antibody titres versus Japanese encephaljtic virus during and after an attack of type 1 dengue fever.

every respect than the $\mathrm{HI}$ test, has little to recommend it, unless a technique can be designed to give information which cannot be obtained from the HI test.

\section{Evidence suggesting the occurrence of inapparent infections}

Neutralizing antibody to dengue- $\mathrm{I}$ virus is to be found in almost all rural-dwelling Malayans by the age of 30 years (I.M.R., 1956), although classical clinical dengue is rarely diagnosed among them. It seems probable that most such infections must therefore cause only minor fever, or be completely subclinical. The United States Army Medical Research Unit (USAMRU) at the Institute for Medical Research, Kuala Lumpur, has found that $30 \%$ of pyrexias of unknown origin (PUO's) reaching hospital show significant rises-in-titre of $\mathrm{HI}$ antibody to the JE-dengue viruses (I.M.R., 1955). This suggests that many dengue infections may cause only 
minor fevers. It seems highly probable, however, that a proportion of dengue infections are completely subclinical. On the other hand, there is evidence that some of the mild febrile forms of dengue are second attacks. Not all cases of pyrexia showing rises of antibody titre to dengue are due to infection with a dengue virus however, and cross-reactions with related viruses must always be kept in mind.

Blanc, Caminopetros \& Manoussakis (1928) showed that inapparent infection could result from experimental inoculation with dengue. A volunteer who did not become ill was shown to have circulating virus and to have developed immunity.

In Table 2 are presented the serological results in girls living in the school hostel at the time of the outbreak who did not become sick. In Table 3, interpretations of the evidence are offered.

It appears, therefore, that although only a small series of cases has been studied, most of the situations we should expect to find in Malaya are represented, namely:

(a) Immunity to dengue due to previous infection (C.K.P., C.Y.L., L.C.L., L.L.F.). Early in the outbreak, sixteen sera were obtained from girls who had not yet become sick. Of these, eight subsequently developed the disease and eight did not. The geometric mean HI titre of those who subsequently escaped clinical disease was $1 / 160$, while that of those who subsequently became cases of dengue was only $1 / 20$.

(b) Partial immunity to dengue due to previous infection. B.S. showed a risein-titre of antibody already present, but did not become ill. S.S.C. (Table 1) was probably a modified clinical case due to previous immunity.

(c) Inapparent infection with dengue (D.T., T.P.T., B.S.).

(d) Intercurrent infection with Japanese encephalitis virus-also inapparent (C.K.P.)

\section{DISCUSSION}

\section{Diagnosis of dengue fever}

In any part of the world where a virus is endemic, diagnosis can be established only if the antibody content of the patient's serum at the beginning of the disease is compared with that in early convalescence. This is because of the common occurrence of residual antibody due to a previous infection. Where antigenically related viruses occur together, residual antibody may be due to a related virus. Generally speaking, if a sufficient increase in antibody content is detected, diagnosis of infection with the virus used in the test or with a closely related virus may be made, but the presence of antigenically related viruses in Malaya greatly complicates the diagnosis of dengue. Casals \& Brown (1954) divided the neurotropic arthropod-borne viruses into groups $A$ and $B$. The dengue viruses belong to group $B$, and other viruses of this group which may cross-react with dengue, and which are or may be present in Malaya, are Japanese encephalitis (Paterson et al. 1952), Uganda S, Zika and Ntaya (Smithburn, 1954a) and Ilheus (Pond et al. 1955).

It is not known whether dengue-2 virus occurs in this area. In India, antibody to dengue-2 was always found in association with dengue-1 antibody and this may represent cross-reaction only (Smithburn, Kerr \& Gatne, 1954). Surveys of rural populations in Malaya (I.M.R., 1956) have brought to light some human sera with 

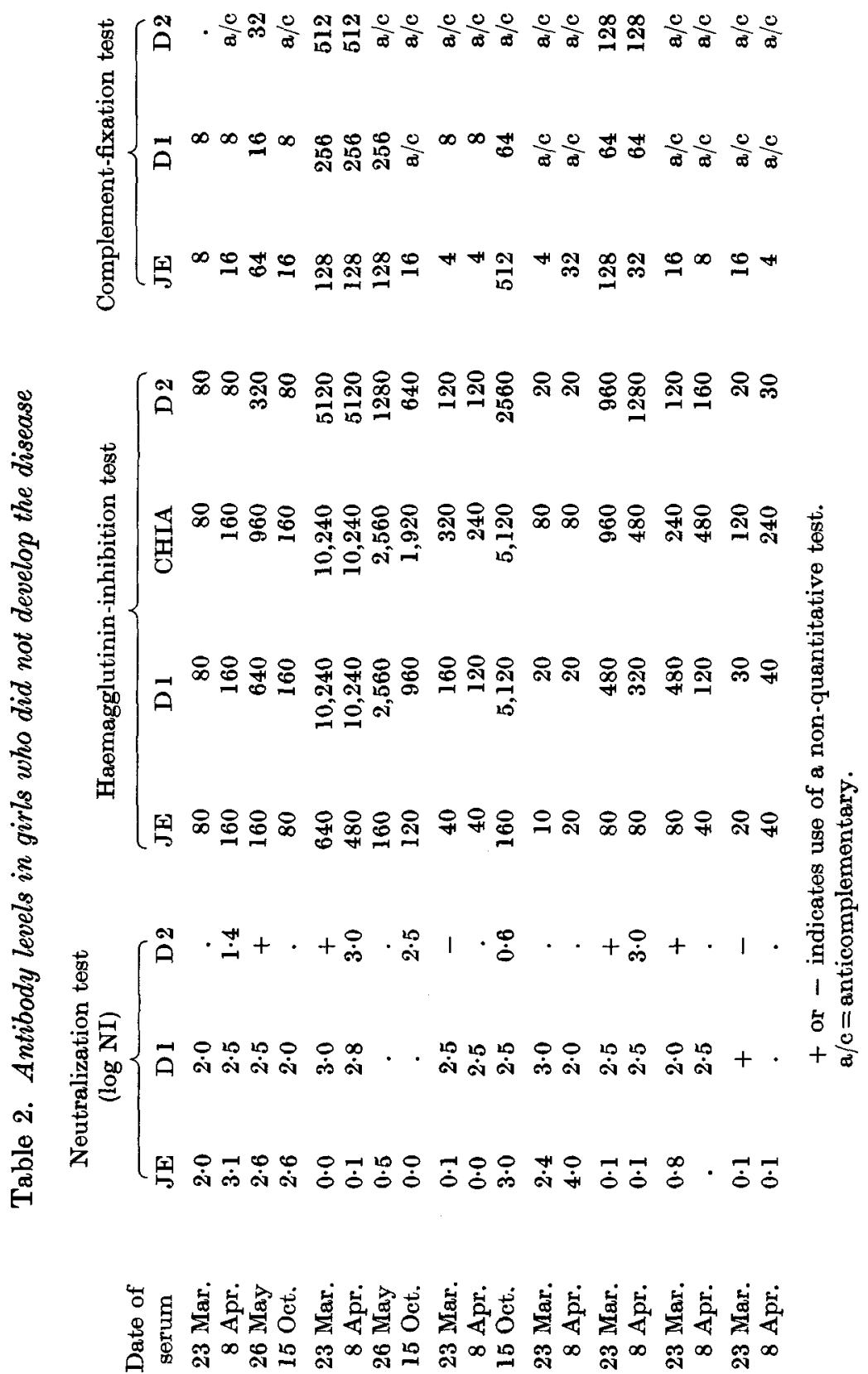

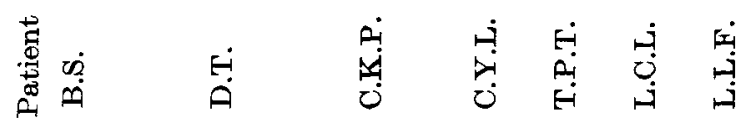


neutralizing antibody to dengue-2 and not to $\mathrm{JE}$ or dengue-1-but this may be evidence of infection with another member of Casal's group B.

All serological tests are marred by variables which are difficult to standardize precisely from test to test. It is therefore highly desirable that all serial serum specimens from a single patient should be tested in the same test and at the same time, as changes in antibody content are much more constant from test to test

\section{Table 3. Suggested interpretations of the serological results on girls who did not become ill in the outbreak}

\section{Findings}

B.S. Antibody to JE and dengue.1 present throughout twofold to fourfold rises-in-titre between 8 April and 26 May by $\mathrm{HI}$ and $\mathrm{CF}$ tests versus all three viruses

D.T. High titres versus dengue but no neutralizing antibody versus JE on 23 March. Falling steadily

C.K.P. Antibody titres indicative of previous infection with dengue-1. No neutralizing antibody versus JE. High titres versus $\mathrm{JE}$ at 15 October

C.Y.L. Neutralizing but little HI antibody versus dengue-1 and $\mathrm{JE}$

T.P.T. High maintained titres of dengue-1 neutralizing antibody and of $\mathrm{HI}$ and CF antibody for all three viruses

L.C.L. Moderate titres of neutralizing and HI antibody versus dengue-l and of HI antibody versus dengue-2

L.L.F. Little evidence of antibody except HI versus CHIA. Falling CF antibody (only JE tested)
Suggested interpretations

Probably previous infection with dengue plus re-infection insufficient to cause illness between 8 April and 26 May

Inapparent infection with dengue-1 recently before 23 March

Previous infection with dengue-1, but probably not recent. Intercurrent infection with JE between 8 April and 15 October

Immune to dengue-1 due to previous infection long before

Probably recent inapparent infection with dengue-1

Probably previous infection with dengue-1. May or may not be recent

Probably previous infection with dengue-1

than differences between single estimations made at different times. In the work reported here, all specimens from a single patient were, as far as possible, tested together. In the complement-fixation test, small variations in the amount of reagents used may make the rise-in-titre during infection with dengue-1 virus greater against JE than against dengue-1, probably because slightly more complement was used in the dengue-1 test than with JE. In the neutralization test the difficulties are much greater and less well understood. It will be noted that while in the test with JE the incubation of serum-virus mixtures was for $30 \mathrm{~min}$. and no attempt was made to supply heat-labile factor, $2 \mathrm{hr}$. incubation periods were used for dengue, and fresh guinea-pig serum was added as a source of heat-labile factor (Sabin, 1950). The former method was adopted originally because it was the method of Paterson et al. (1952) and the latter was recommended by Sabin (1956). Had heat-labile factor been added to the JE tests, higher titres of antibody might have been recorded, but the preparation of large volumes of fresh guinea-pig serum is expensive and time-consuming, and was therefore omitted since a satisfactory test with JE is obtained without it. Clearly the JE tests may not be quantitatively comparable with the dengue tests. 
One difficulty which must be accepted is that in order to test serial samples of serum together, they must be stored for different periods. Storage at $-20^{\circ} \mathrm{C}$ seems to be the best available method.

The relations of the geometric means of the results of tests on the patients in this study are shown in Fig. 11.* Table 1 summarized the rises in titre obtained.
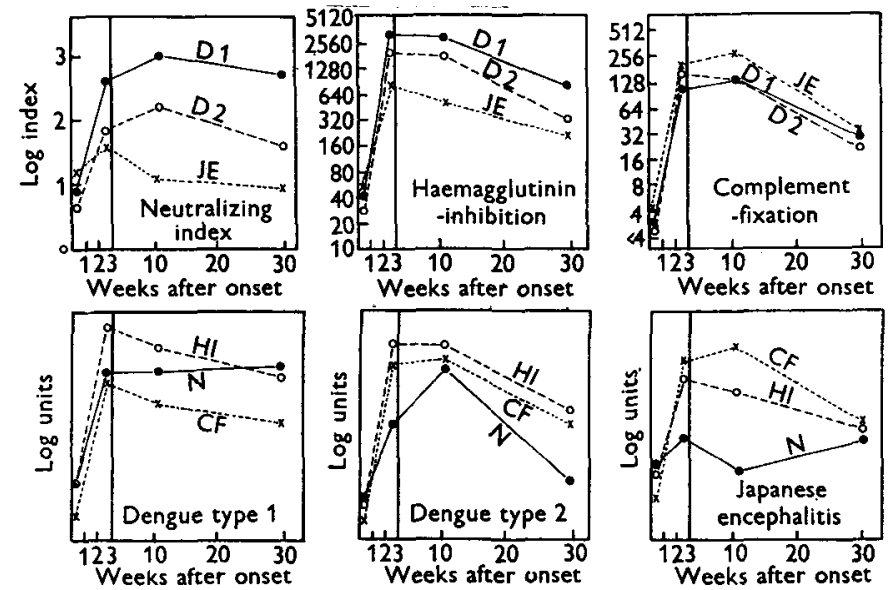

Fig. 11. Geometric mean antibody levels during and after type 1 dengue fever.

The neutralization test is clearly the only one which enables clear distinctions to be drawn between antibodies to JE and to dengue. In many cases, distinction between the two types of dengue is possible only if serial serum specimens are examined over several months. Apparent cross-reactions between JE and dengue in the neutralization test were noted by Smithburn (1954b) in patients in Japan convalescent from JE. Sabin (1956) mentions that he obtained heterologous neutralizing antibody responses in monkeys inoculated with human dengue virus.

In an area where more than one virus of Casal's B group occurs, the HI test is of value mainly in the recognition of cases in an outbreak where some have been clearly identified; or in the screening of healthy persons or cases of pyrexia of unknown origin for evidence of infection with a virus of the group. In a country where only one virus of the group occurs, this test is of much greater value, an example apparently being $\mathrm{JE}$ in Japan.

The complement-fixation test by the methods used here gives no information not provided by the easier and more reliable $\mathrm{HI}$ test. There is therefore little use for it in a country where more than one of these antigenically related viruses occur.

\section{The rate of appearance and disappearance of antibodies}

It has already been pointed out that little work has been published on this subject. Melnick, Curnen \& Sabin (1948) reported a laboratory infection with dengue-1 virus where the neutralizing antibody increased more than 4000 -fold

* Fig. 11 has appeared in the Medical Journal of Malaya (Smith, 1956a) and is reproduced here by permission of the editor. 
between the 2nd and 13th day of disease. Hotta (1952) studied four experimental dengue infections of which two had had dengue previously. The re-infected patients showed a 1000-fold rise in neutralizing antibody in 1 week, while the previously uninfected patients took 3 weeks for antibody to increase about 300 -fold. In this series most patients had neutralizing indices of 100-10,000 to dengue-1 by the 2nd or 3rd week of disease, but two patients did not show a significant rise in neutralizing antibody until after the 3rd week. Increases in antibody to dengue-2 were smaller, and only a few patients showed increase versus JE. There was no fall in titre of neutralizing antibody versus dengue-1 up to the 30th week after onset, but by that time the level of antibody to dengue-2 had dropped to less than a neutralizing index of 50 .

Sweet \& Sabin (1954) found that HI antibodies were apparent within 7 days for the homologous virus (the one inoculated into the volunteers-say dengue-1). Owing to the presence of HI antibody, in many of the patients reported here, to antigenically related viruses such as JE, the initial levels of $\mathrm{HI}$ antibody to all four viruses was about the same (mean around 40). A very significant rise-in-titre against all four viruses was apparent by the 2nd or 3rd week (16 to 64-fold mean). The rises-in-titre were largest and most consistent against dengue-1. The rate of fall-off (about fourfold in 30 weeks) was about the same for all four viruses.

Sabin \& Young (1948), using the complement-fixation test in the study of experimental cases, found that the antibody level reached a peak between the 2nd and 6th week after inoculation. Homologous (dengue-1) antibody reached 64 to 256 , and was still 4 to 16 after more than 4 years. Heterologous (dengue-2) antibody reached lower levels (about 16) and in some cases became negative in 6 months. These tests were done, using 4 units of benzene-extracted antigen. Sabin \& Sweet (1954) found that they could not distinguish antibodies to dengue-1 and dengue-2 in infections with dengue-1 by the complement-fixation test. Using 128 units of JE antigen, they were able to distinguish JE from dengue antibodies. In this series no real difference could be detected between the three viruses. Titres were maximum between 2 and 12 weeks after onset and fell about fourfold by the 30th week.

\section{The implications in serum antibody surveys}

Serum antibody surveys have been carried out widely in the last decade or so as a means of finding out the distribution of infections with various viruses. There are, however, considerable difficulties in doing this for the Casal's group B viruses when more than one occurs in the area under study. The neutralization test, being most specific, is of the most value and a technique of analysis for survey neutralization tests is described by Smith and Westgarth (1957).

In a survey of five rural communities in Malaya (I.M.R., 1956) using this technique it was found that many sera had antibodies against two or three viruses of Casal's group B (JE, dengue-1, dengue-2). When they were tested against yellow fever (YF) virus which is also a member of the group, a number were found to be positive. When the sera positive to YF were compared with the negatives, however, it was found that a much higher proportion of the positives had neutralizing 
antibody to JE and dengue than the negatives. A $\chi^{2}$ test showed that for the difference $P$ was less than $0 \cdot 002$. The most probable explanation of this seems to be that the apparent YF antibodies were cross-reacting JE and/or dengue antibodies.

If it were practicable to test all sera for antibodies against all possible viruses it might be assumed that the most recent infection was with the virus against which there was the highest titre of antibody. But where several related viruses occur, as in Malaya, multiple infections may lead to anomalies. For example, Smithburn $(\mathbf{1 9 5 4 b )}$ found that monkeys immunized against both Ilheus and St Louis viruses developed neutralizing antibody in high titre also against JE and West Nile viruses -all these viruses falling into Casal's group B. Hammon, Sather, Lennette \& Reeves (1956) and Hammon \& Sather (1956) have produced evidence suggesting that infections with one or more B-group viruses may confer immunity against other members of the group.

We can say of a positive test in a survey that if the serum is positive against only one virus, then there has been an infection probably with that virus, but possibly with a virus not included in the test, and which has, perhaps, not yet been isolated. Work by USAMRU has suggested that some of the dengue-like fevers found in Malaya are caused by at least one virus which is not a dengue virus, but is not yet completely characterized. If a serum is positive against more than one virus, then it is at present impossible to decide whether this represents cross-reaction due to a single infection (e.g. 3 months after dengue-1 infection) or to multiple infections. Some clues may be obtained from relative titres perhaps in the HI test.

It was hoped that work and expense could be saved by screening sera by the HI test, then testing those with $\mathrm{HI}$ antibody for neutralizing antibody. This has not been realized, however, as it has been found, in animals at any rate, that both HI and neutralizing antibody can occur independently.

\section{SUMMARY}

1. Sera from an outbreak of about forty cases of dengue fever due to dengue-1 virus have been studied using the neutralization, haemagglutinin-inhibition, and complement-fixation tests.

2. The neutralization test was the most specific and the complement-fixation test the least so.

3. The neutralization test is essential for clear identification of the causal virus by serological means, and serial serum specimens from each patient must be examined.

4. The haemagglutinin-inhibition test can be used to screen patients in outbreaks where some cases have been fully identified by neutralization tests.

5. Homologous neutralizing antibodies persist in high titre for at least 30 weeks after infection, while heterologous antibodies have disappeared by that time.

6. Both haemagglutinin-inhibiting and complement-fixing antibodies to homologous and heterologous viruses usually persist for at least 30 weeks, although the homologous titres tend to be highest. 
7. The implications of these findings in serological surveys are discussed.

8. Some evidence suggesting the occurrence of inapparent infections during the epidemic is presented.

I am greatly indebted to my staff for help with this work: especially to my senior technician, Che Ali bin Mohamed Amin, and to Che Mohamed bin Omar who drew the figures.

\section{REFERENCES}

Blanc, G., Caminopetros, J. \& Manoussakis, E. (1928). Quelques recherches expérimentales sur la dengue. Bull. Soc. Pat. exot. 21, 525.

Casals, J. \& Brown, L. V. (1954). Haemagglutination with arthropod-borne viruses. J. $\exp$. Med. 99, 429.

Casals, J. \& Olitsky, P. K. (1951). A specific complement-fixation test for infection with poliomyelitis virus. J. exp. Med. 94, 123.

Chanock, R. M. \& Sabin, A. B. (1954). The haemagglutinin of Western equine encephalitis virus : recovery, properties and use for diagnosis. J. Immunol. 73, 337.

Fulton, F. \& Dumbelt, K. R. (1949). The serological comparison of strains of influenza virus. J. gen. Microbiol. 3, 97.

Hammon, W. MCD. \& SATHER, G. E. (1956). Immunity of hamsters to West Nile and Murray Valley viruses following immunization with St Louis and Japanese B. Proc. Soc. exp. Biol., N.Y., 91, 521.

Hammon, W. McD., Sather, G. E., Lennette, E. H. \& Reeves, W. C. (1956). Serological responses to Japanese $B$ vaccine of children and horses immune to $\mathrm{St}$ Louis virus. Proc. Soc. exp. Biol., N.Y., 91, 517.

Нотта, S. (1952). Experimental studies on dengue: I. Isolation, identification and modification of the virus. $J$. infect. Dis. 90,1 .

I.M.R. (1955). Rep. Inst. med. Res., Malaya, for 1954, p. 96.

I.M.R. (1956). Rep. Inst. med. Res., Malaya, for 1955. In the Press.

Mackie, T. J. \& McCartiney, J. E. (1950). Handbook of Practical Bacteriology, 8th ed. p. 256. Edinburgh: E. and S. Livingstone.

Melnick, J. L., CURnen, E. C. \& Sabin, A. B. (1948). Accidental laboratory infection with human dengue virus. Proc. Soc. exp. Biol., N.Y., 68, 198.

Paterson, P. Y., Ley, H. L., Wisseman, C. L., Pond, W. L., Smadel, J. E., Diercks, F. H., Hetherington, H. D. G., Sneath, P. H. A., Witherington, D. H. \& Lancaster, W. E. (1952). Japanese encephalitis in Malaya. I. Isolation of virus and serological evidence of human and equine infections. Amer. J. Hyg. 56, 320.

Pond, W. L., Russ, S. B., McCrumb, F. R., Dingle, J. H., Ley, H. L. \& Schmidt, J. (1955). Antibodies to arthropod-borne viral diseases in sera from residents of Southeast Asia. Bact. Proc. p. 66.

SaBIN, A. B. (1950). The dengue group of viruses and its family relationships. Bact. Rev. 14, 225.

Sabrn, A. B. (1956). Chapter on dengue in Diagnostic Procedures for Virus and Rickettsial Diseases, 2nd ed. New York: American Public Health Association (in the Press).

Sabin, A. B., \& Young, I. (1948). A complement-fixation test for dengue. Proc. Soc. exp. Biol., N.Y., 69, 478.

SMAdEL, J. E. (1952). Serological reactions in viral and rickettsial infections. In Rivers, T. M., Viral and Rickettsial Infections of Man, 2nd ed. p. 75. Philadelphia, London, Montreal: Lippincott, 1952.

Sмгтн, C. E. G. (1956a). A localized outbreak of dengue fever in Kuala Lumpur: epidemiological and clinical aspects. Med. J. Malaya, 10, 289.

SMrTH, C. E. G. (1956 b). Isolation of three strains of type 1 dengue virus from a local outbreak of the disease in Malaya. J. Hyg., Camb. 54, 569.

SmithBURN, K. C. $(1954 a)$. Neutralizing antibodies against arthropod-borne viruses in the sera of long-time residents of Malaya and Borneo. Amer. J. Hyg. 59, 157. 
SmithbuRn, K. C. (1954b). Antigenic relationships among certain arthropod-borne viruses as revealed by neutralization tests. J. Immunol. 72, 376.

SmithbURN, K. C., KFrR, J. A. \& Gatne, P. B. (1954). Neutralizing antibodies against certain viruses in the sera of residents of India. J. Immunol. 72, 248.

STOKER, M. G. P. (1953). Variation in complement-fixing activity of Rickettsia burneti during egg adaptation. J. Hyg., Camb., 51, 311.

Sweet, B. H. \& Sabin, A. B. (1954). Development of different antibodies in human beings experimentally infected with type 1 or type 2 dengue viruses. Fed. Proc. 13, 513.

(MS. received for publication 30. vII. 56) 